\title{
GC/MS Analysis of Fatty Acids in Italian Dry Fermented Sausages
}

\author{
Angelo Liguori ${ }^{1, *}$, Emilia Lucia Belsito ${ }^{1}$, Maria Luisa Di Gioia ${ }^{1}$, Antonella Leggio ${ }^{1}$, Francesca \\ Malagrinò ${ }^{1}$, Emanuela Romio ${ }^{1}$, Carlo Siciliano ${ }^{1}$ and Antonio Tagarelli ${ }^{2}$
}

\author{
${ }^{I}$ Dipartimento di Farmacia e Scienze della Salute e della Nutrizione, Università della Calabria, edificio polifunzionale, \\ I-87036, Arcavacata di Rende, Cosenza, Italy \\ ${ }^{2}$ Dipartimento di Chimica e Tecnologie Chimiche, Università della Calabria, ponte P. Bucci, cubo 12D, I-87036, \\ Arcavacata di Rende, Cosenza, Italy
}

\begin{abstract}
The present investigation reports a study about the evolution, during ripening, of the fatty acid profile and the fatty acid composition in acylglycerols of three different fermented sausages industrially produced in the Calabria region (Southern Italy). Statistical analysis (ANOVA) was applied to the results obtained for the profiles to check all the differences between samples. The study comprised also an evaluation of the lipid oxidation level. All kind of sausages showed a free fatty acids profile in which the monounsaturated fatty acids were predominant, followed by saturated and polyunsaturated fatty acids. In acylglycerols, a low content in linoleic acid (approximately $2 \%$ of total methyl esters) was displayed, while that found in the free fatty acids profile was higher (approximately 17\% of total FFAs). In addition, the generation of aldehydes through secondary lipid oxidation was clearly confirmed after long ripening period by classical qualitative colorimetric method supported by ${ }^{1} \mathrm{H}$ NMR spectroscopy. The differences in fatty acids profiles observed in the free fatty acids and the acylglycerol fractions were certainly due to the high selectivity of lypase activity during the ripening.
\end{abstract}

Keywords: Acylglycerols, dry fermented sausages, fatty acids, gas chromatography-mass spectrometry, lipolysis.

\section{INTRODUCTION}

Dry fermented sausages are traditional meat pork products mainly manufactured in Countries of the Southern Europe like Italy [1]. In Calabria region (Southern Italy) several types of fermented sausages are still produced using traditional manufacturing processes but there is an increase in the demand for industrial production of these products. In the last decade numerous studies concerning technological, chemical, and sensory characterization of traditional dry fermented meat products have been performed [2]. The analysis of dry fermented sausages generally points out on some important parameters: breakdown products of lipolysis [3, 4] and proteolysis [5] i.e. peptides, amino acids [6], free fatty acids (FFAs) that contribute to the nutritional characteristics of fermented meat. Much attention is also paid to the determination of products of further degradation such as biogenic amines [7,8] or compounds derived from oxidation of polyunsaturated fatty acids (PUFAs) $[9,10]$. The analysis of fatty acids has become increasingly important in a modern society with dietary recommendations favoring a low intake of fats because more people are aware of their nutritional implication [11]. Furthermore, the

\footnotetext{
*Address correspondence to this author at the Dipartimento di Farmacia e Scienze della Salute e della Nutrizione, Università della Calabria, edificio polifunzionale, I-87036, Arcavacata di Rende, Cosenza, Italy;

Tel: +39-0984-493205; Fax: +39-0984-493205;

E-mail: A.Liguori@unical.it
}

growing interest in the control of the composition in acylglycerols and FFAs of sausages mainly is attributable to the necessity of producing "healthy" foods characterized by saturated/unsaturated fatty acid ratios all in favor of the latter ones. Epidemiological and biochemical studies have provided a great deal of evidence about the protective effect of $\omega-3$ PUFAs against some common tumors, rheumatoid arthritis and cardiovascular diseases (CVD) [12-15]. The investigation of fatty acid composition in the lipid fraction of sausages could provide information about changes in the content in saturated fatty acids (SFAs), monounsaturated fatty acids (MUFAs) and polyunsaturated fatty acids (PUFAs) occurring during the ripening. This point should be of interest for the evaluation of the changes of nutritional characteristics of these products. In fact, modifications of the PUFA and MUFA content can have possible effects related to a low or high consumption of the fermented sausages. In this context, detailed information about the fatty acid profile provides researchers with the necessary knowledge in this field, as well as consumers about the shelf-life and acceptance of this kind of meat products.

In the present study the total lipid fraction extracted from three different Calabrian fermented sausages (known as "salsiccia", "spianata" and "soppressata") was analyzed by GC/MS. These sausages are typically produced in the South of Italy and represent a significant part of the culinary traditions of these regions. Moreover they are widely exported to many European Countries. The investigation 
covered the determination of fatty acid profiles in the respective acylglycerol portions as well as the composition of free fatty acids during a long time period of ripening (80 days).

\section{MATERIAL AND METHODOLOGY}

\subsection{Sausages Formulation and Processing}

The dry fermented sausages used in this study were prepared at an industrial establishment sited in the province of Cosenza (Calabria region, Southern Italy) following the current Italian industrial processing technology. Pork meat was ground and then mixed. Once out of the grinder and before mixing, sodium chloride $(2.4 \% \mathrm{w} / \mathrm{w})$ was added. Moreover, sodium nitrite $(0.01 \% \mathrm{w} / \mathrm{w})$, sodium nitrate $(0.01 \% \mathrm{w} / \mathrm{w})$, antioxidants (ascorbic acid, $0.02 \% \mathrm{w} / \mathrm{w})$, sugars (dextrose and sucrose, $0.45 \% \mathrm{w} / \mathrm{w}$ ), and spices (red hot pepper for "salsiccia" and "spianata", $0.6 \%$ w/w; black pepper and other spices for "soppressata" $0.6 \% \mathrm{w} / \mathrm{w}$ ), and aromas $(1 \% \mathrm{w} / \mathrm{w})$ were added during mixing. Microbial starter formulations were also added as follows: i) SAGA T $(0.01 \% \mathrm{w} / \mathrm{w}, 2 \times 1010 \mathrm{ufc} / \mathrm{g}$ Pediococcus pentosaceus and Staphylococcus carnosus, Kerry Ingredients \& Flavours Italia S.p.A., Mozzo, Bergamo, Italy) for "salsiccia" and "soppressata"; ii) LH30 (Lactobacillus helveticus fratelli Pagani, Milano, Italy) for "spianata". Mixtures were stuffed in casings and then spiked to allow entrapped air to escape. The sausages were stored in a warm room to dry under the following conditions: $24-26{ }^{\circ} \mathrm{C}$ at $75-80 \%$ relative humidity (RH) for 3 days, then $12-14{ }^{\circ} \mathrm{C}$ at $60-70 \% \mathrm{RH}$ in the last days of the curing process. After 20 days, sausages were then stored under vacuum-packaging for the entire ripening period (80 days).

\subsection{Sampling}

The sausages were sampled and analyzed in triplicate (three different sources) during three different periods of ripening (20 days: samples sal20 and spi20; 40 days: samples sal40, sop40 and spi40; 80 days: samples sal80, sop80 and spi80). Samples were homogenized in a household kitchen-type blender before analysis.

\subsection{Physicochemical Analyses}

Total nitrogen $(\mathrm{TN})$ and protein nitrogen $(\mathrm{PN})$ were determined following the Kjeldahl method [16]. Moisture was determined according to the official methods of analysis [17]. Total lipids extracts were obtained by Soxhlet extraction according to the procedure reported in the literature [18].

\subsection{Determination of Fatty Acid Composition}

An aliquot of lipid extract (200 $\mathrm{mg}$ ) was dissolved in 3 $\mathrm{mL}$ of $n$-hexane. A methanolic solution $(5 \mathrm{~mL})$ of sodium methoxide $(10.1 \mathrm{mg} / \mathrm{mL})$ was then added. A $20 \%$ excess sodium methoxide was used: this excess was calculated assuming that fat is constituted exclusively by triolein. The mixture was stirred at room temperature for $5 \mathrm{~min}$. Afterwards, the hexane was separated from the methanolic phase. Then the methanolic phase was washed twice with hexane. The hexane was finally removed under reduced pressure conditions. The residue was dissolved in dichloromethane and analyzed by GC/MS. Fatty acid methyl esters (FAMEs) were identified by comparing the retention times of the chromatographic peaks with those obtained with the methyl esters from a mixture prepared with fatty acids from Sigma-Aldrich (Milano, Italy). The structural assignment was further confirmed by comparing their mass spectra with those of reference standards.

In a second time, the methanolic phase, containing the FFAs as carboxylate anions, was evaporated under reduced pressure. The residue was acidified with aqueous $\mathrm{HCl} 1 \mathrm{~N}$ and then extracted with diethyl ether $(5 \times 3 \mathrm{~mL})$. The combined ethereal extracts were washed once with a saturated sodium chloride aqueous solution, dried over anhydrous sodium sulfate $\left(\mathrm{Na}_{2} \mathrm{SO}_{4}\right)$ and paper filtered and evaporated to dryness under vacuum.

\subsection{FFAs Quantitative Analysis}

Fatty acids were identified by comparison of their retention times to standards. Methyl pentadecanoate (C15:0) purchased from Sigma-Aldrich, normally not present in the lipid extracts, was used as the internal standard $(20 \mathrm{mg} / \mathrm{mL})$. This was added to aliquots of lipid extracts in order to determine the quantity of each fatty acid in the sample analyzed. FFAs were quantified as their corresponding FAMEs. To this aim, the residue obtained from transesterification was treated with a large excess of a $0.66 \mathrm{~N}$ dichloromethane solution of diazomethane [19-21]. Until the solution exhibited a constant pale yellow color. After $30 \mathrm{~min}$ the organic solvent was removed under reduced pressure conditions, the residue was dissolved in $5 \mathrm{~mL}$ of dichloromethane and analyzed by GC/MS [7, 22].

FAMEs standard solutions: A mixture of standard free fatty acids $(21.8 \mathrm{mg}$ of myristic acid; $22.0 \mathrm{mg}$ of palmitic acid; $26.9 \mathrm{mg}$ of palmitoleic acid; $25.3 \mathrm{mg}$ of linolenic acid; $23.8 \mathrm{mg}$ of linoleic acid; $30.4 \mathrm{mg}$ of oleic acid; $22.4 \mathrm{mg}$ of stearic acid) was treated with a large excess of a $0.66 \mathrm{~N}$ dichloromethane solution of diazomethane using the procedure described above. The residue was dissolved in 10 $\mathrm{mL}$ of methylene chloride (solution A). Four stock solutions were then prepared starting from solution $\mathrm{A}$ : an aliquot of $0.1 \mathrm{~mL}$ of methyl pentadecanoate standard solution was added to 1, 2, 3 and $4 \mathrm{~mL}$ of solution $\mathrm{A}$ and each stock solution was diluted to $5 \mathrm{~mL}$ with methylene chloride to create standard solutions. $1 \mu \mathrm{L}$ of each FAMEs standard solution was analyzed by GC/MS.

\subsection{GC/MS Analysis of FFAs and FAMEs}

Analyses of FFAs and FAMEs were carried out using a 6890N Network GC System (Agilent Technologies Inc., Palo Alto, CA, U.S.A.) equipped with a HP- 5MS (30 m x 0.25 $\mathrm{mm}$ i.d., $0.25 \mu \mathrm{m}$ film thickness) capillary column and with a 5973 Network MSD mass spectrometer, operated in electron-impact ionization mode $(70 \mathrm{eV})$. GC-MS analyses were carried out in split mode (split ratio 1:50), using helium as the carrier gas $(1 \mathrm{~mL} / \mathrm{min}$ flow rate). The injector temperature was fixed at $250{ }^{\circ} \mathrm{C}$. The sample volume injected was $1 \mu$ l. Oven temperature was held at $150{ }^{\circ} \mathrm{C}$ for 2 min and then programmed at $5{ }^{\circ} \mathrm{C} / \mathrm{min}$ to a final temperature of $280{ }^{\circ} \mathrm{C}$, where it was maintained for $5 \mathrm{~min}$. 


\subsection{Kreis Test Methodology}

In each experiment, a known quantity of lipid extract (2 g) was mixed with $2 \mathrm{~mL}$ of concentrated $\mathrm{HCl}$ in a test tube for $30 \mathrm{~s}$. Then $2 \mathrm{~mL}$ of a $0.1 \%$ solution of phloroglucinol in diethyl ether were added and mixed thoroughly with the lipid-acid mixture [23]. A pink color formation indicated that the fat was slightly oxidized while a red color indicated that the fat was definitely oxidized.

\subsection{NMR Analysis}

For ${ }^{1} \mathrm{H}$ NMR analysis, aliquots of $200 \mathrm{mg}$ of the lipid extracts were dissolved in $0.7 \mathrm{~mL}$ of deuterated chloroform $\left(\mathrm{CDCl}_{3}\right)$ in a $5 \mathrm{~mm} \mathrm{NMR} \mathrm{tube.} \mathrm{All} \mathrm{spectra} \mathrm{were} \mathrm{recorded} \mathrm{at}$ $25 \pm 0.1{ }^{\circ} \mathrm{C}$ under temperature control, using a Bruker Avance 300 Ultrashield spectrometer equipped with a 5-mm probe with Z-axis gradient coils. Spectra were obtained at the ${ }^{1} \mathrm{H}$ frequency of $300.132 \mathrm{MHz}$ applying a standard zg90 pulse sequence, with the lock on the deuterium resonance of the solvent. Chemical shift values $(\delta)$ were reported in ppm by referencing them to tetramethylsilane (TMS) used as the internal standard.

\subsection{Statistical Analysis}

Mean and standard deviation of data are shown in all tables. The differences between samples obtained at the three periods of storage were tested for each type of sausage by applying the Kruskal-Wallis test and Mann-Whitney U test to both FAME and FFA concentration data. The KruskalWallis test and Mann-Whitney $U$ test are the analogous nonparametric methods of one-way between-groups of variance (analysis of variance, ANOVA) and t-test, respectively. Nonparametric techniques are also called "distribution free methods", since they are not dependent on a given distribution (such as in the case of ANOVA) but generally work for a broad range of different distributions. Since our statistical samples were not large enough to assume that the sampling distributions were normal, a nonparametric approach to treatment of data was necessary.

\section{RESULTS AND DISCUSSION}

The results for proximate composition of the three different types of dry sausages are reported in Table 1. It can be observed from the data obtained that moisture in the "salsiccia" batches is low (27-30\%): this fact is probably due to the small size and to the tight casing that allows a great water loss. Instead, the "soppressata" and the "spianata" samples that are prepared in larger casings are characterized by a moisture content that ranged between 37.5 and $41.2 \%$. Table 1 gives also the protein percentages found for the dry sausages studied. These values ranged between $32.1 \%$ and $38.8 \%$. The lipase activity influences the FFAs content during the drying and ripening steps $[24,25]$. The total fat amount in the analysed sausages varied between $24.8 \%$ and $32.6 \%$. Nevertheless, the fat obtained from all types of sausages by solvent extraction may also contain non-fat material. The analysis of total lipid extract often fails in accurately estimating nutritional values of biological materials. Evaluation of total fatty acids represents a better alternative for assessment of nutritional value than extractable lipids.

In dry sausages fatty acids are present both as esters linked to glycerol and phospholipids and as free (unesterified) fatty acids. The determination of fat composition in dry fermented sausages either in the acylglycerol or in the unesterified form was carried out by transesterification of the total lipid extract using a large excess of sodium methoxide.

The methods which utilize methanol in acidic medium for the transesterification of acylglycerols cannot be adopted because the results could be affected by the esterification of the FFAs present in the fat [26]. On the other hand, basecatalyzed transesterification of acylglycerols can suffer from the presence of FFAs that could neutralize the reaction environment thus leading to an incomplete transesterification [27]. The use of a large excess of sodium methoxide in dry environment enables the neutralization of the FFAs converting them rapidly into the corresponding sodium salts that are retained on the methanolic phase. At the same time,

Table 1. Moisture, protein and lipid content of the analyzed sausages from Southern Italy.

\begin{tabular}{|c|c|c|c|c|}
\hline Sausages & Samples & Moisture (Mean \pm SD) & Protein(Mean \pm SD) & Fat $($ Mean \pm SD) \\
\hline \hline \multirow{3}{*}{ "Salsiccia" } & Sal20 & $27.9 \pm 0.7$ & $37.5 \pm 0.7$ & $32.6 \pm 0.6$ \\
\cline { 2 - 5 } & Sal40 & $27.4 \pm 1.1$ & $37.8 \pm 1.1$ & $29.5 \pm 0.9$ \\
\cline { 2 - 5 } & Sal80 & $29.9 \pm 1.1$ & $38.8 \pm 0.6$ & $24.7 \pm 0.9$ \\
\hline \multirow{2}{*}{ "Soppressata" } & Sop40 & $41.2 \pm 0.7$ & $32.1 \pm 1.1$ & $26.3 \pm 0.9$ \\
\cline { 2 - 5 } & Sop80 & $38.7 \pm 1.1$ & $33.3 \pm 0.9$ & $27.2 \pm 0.7$ \\
\cline { 2 - 5 } & Spi20 & $37.6 \pm 0.5$ & $32.2 \pm 1.1$ & $28.3 \pm 0.7$ \\
\cline { 2 - 5 } & Spi40 & $37.5 \pm 1.2$ & $33.1 \pm 1.1$ & $29.4 \pm 0.5$ \\
\hline
\end{tabular}

Data are expressed as mean value \pm SD in percentage, $(n=3)$. Measures were performed in triplicate. 
the use of an excess sodium methoxide ensures, through the complete transesterification of acylglycerols, the formation of fatty acid methyl esters (FAMEs) that are soluble in hexane. GC/MS analysis of the hexane layers showed the presence of FAMEs (Fig. 1). Their identification was achieved by comparing their individual peak retention times and mass spectra with those of reference standards.

FFAs were recovered after acidification of the methanolic solution and were then subjected to the derivatization procedure and measurement. In fact, fatty acids need to be converted into FAMEs in order to improve their volatility and thus ensuring better gas chromatographic peak shape. Derivatization was performed with diazomethane according to the method of Schlenlg and Gellerman (1960) [28] that enables the conversion of the FFAs into the corresponding methyl esters. Table 2 reports the data obtained for FFAs in all products considered. The three "salsiccia" batches showed a lower content of FFAs (about $6 \%$ of total fat) than those recovered in the samples from "soppressata" and "spianata" (7.5-10\% ca of total fat).

The percentage of FFAs in the total fat was calculated as the sum of individual fatty acids. The main identified fatty acids in the three different types of sausages were: oleic, palmitic, linoleic, stearic, palmitoleic and myristic acid. This profile coincides basically with that found by other authors in pork fat [29].

All the examined samples (Table 2) showed a higher content of MUFAs and PUFAs than SFAs. In particular, the saturated/unsaturated free fatty acid ratio (S/U) achieves values around 0.22 and 0.36 . Oleic acid (C18:1 cis-9) was predominant among MUFAs, being also the most prevalent individual FFA in all kinds of sausages, with values around 58-68\%. Linoleic acid (C18:2 cis-9, cis-12) was the dominating PUFA with values around 9-18\%. SFAs were also determined, with palmitic acid (C16:0) contributing for the highest amounts (12-18\%); stearic acid (C18:0) being

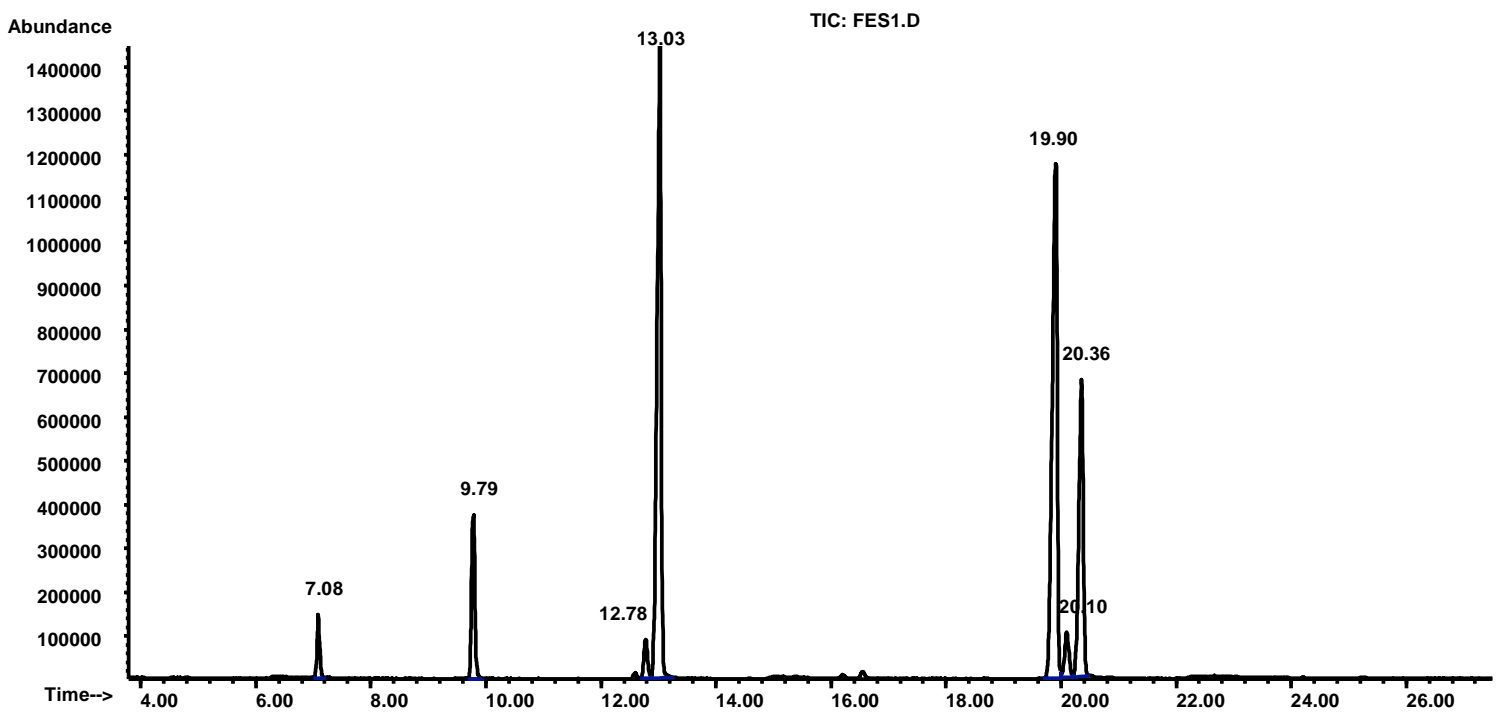

Fig. (1). GC/MS analysis of FAMEs obtained from the transesterification of sample sal20 (r.t. 7.08 myristic acid methyl ester; r.t. 9.79 pentadecanoic acid methyl ester (reference standard); r.t. 12.78 palmitoleic acid methyl ester; r.t. 13.03 palmitic acid methyl ester; r.t. 19.90 oleic acid methyl ester; r.t. 20.10 linoleic acid methyl ester; r.t. 20.36 stearic acid methyl ester).

Table 2. FFAs profile of the analyzed sausages form Southern Italy, determined by GC/MS.

\begin{tabular}{|c|c|c|c|c|c|c|c|c|}
\hline & \multicolumn{3}{|c|}{ "Salsiccia" } & \multicolumn{2}{|c|}{ "Soppressata" } & \multicolumn{3}{|c|}{ "Spianata" } \\
\hline & Sal20 & Sal40 & Sal80 & Sop40 & Sop80 & Spi20 & Spi40 & Spi80 \\
\hline FFAs in total fat & $5.70 \pm 0.12$ & $6.12 \pm 0.11$ & $6.73 \pm 0.20$ & $9.92 \pm 0.18$ & $8.66 \pm 0.16$ & $7.48 \pm 0.27$ & $7.54 \pm 0.19$ & $8.33 \pm 0.26$ \\
\hline Myristic acid $\left(\mathrm{C}_{14: 0}\right)$ & $1.95 \pm 0.05$ & $1.22 \pm 0.04$ & $1.37 \pm 0.05$ & $0.98 \pm 0.02$ & $1.11 \pm 0.04$ & $1.14 \pm 0.03$ & $1.46 \pm 0.04$ & $1.37 \pm 0.04$ \\
\hline Palmitic acid $\left(\mathrm{C}_{16: 0}\right)$ & $17.09 \pm 0.06$ & $12.53 \pm 0.03$ & $14.46 \pm 0.03$ & $12.15 \pm 0.05$ & $17.72 \pm 0.08$ & $14.00 \pm 0.09$ & $11.96 \pm 0.04$ & $16.18 \pm 0.02$ \\
\hline Stearic acid $\left(\mathrm{C}_{18: 0}\right)$ & $6.92 \pm 0.13$ & $6.23 \pm 0.07$ & $7.05 \pm 0.01$ & $5.24 \pm 0.14$ & $7.72 \pm 0.10$ & $5.88 \pm 0.06$ & $6.99 \pm 0.11$ & $6.37 \pm 0.12$ \\
\hline Palmitoleic acid $\left(\mathrm{C}_{16: 1}\right)$ & $4.60 \pm 0.02$ & $3.25 \pm 0.05$ & $3.36 \pm 0.02$ & $3.78 \pm 0.11$ & $2.94 \pm 0.03$ & $3.45 \pm 0.03$ & $3.62 \pm 0.04$ & $3.32 \pm 0.04$ \\
\hline Oleic acid $\left(\mathrm{C}_{18: 1}\right)$ & $58.56 \pm 0.01$ & $58.84 \pm 0.05$ & $62.16 \pm 0.05$ & $68.72 \pm 0.20$ & $58.61 \pm 0.07$ & $58.56 \pm 0.16$ & $60.95 \pm 0.04$ & $62.50 \pm 0.12$ \\
\hline Linoleic acid $\left(\mathrm{C}_{18: 2}\right)$ & $10.87 \pm 0.02$ & $17.93 \pm 0.03$ & $11.59 \pm 0.05$ & $9.13 \pm 0.03$ & $11.91 \pm 0.02$ & $16.93 \pm 0.02$ & $14.96 \pm 0.04$ & $10.28 \pm 0.07$ \\
\hline $\mathrm{S} / \mathrm{U}$ & 0.35 & 0.25 & 0.29 & 0.22 & 0.36 & 0.26 & 0.26 & 0.31 \\
\hline
\end{tabular}

Data are expressed as mean value \pm SD in percentage, $(n=3)$. Measures were performed in triplicate. S/U: saturated/unsaturated free fatty acid ratio. 
below $8 \%$ and the myristic acid (C14:0) concentration being less than $2 \%$.

To this aim the FAMEs recovered in the hexane phase obtained from the transesterification were subjected to quantitative analysis. The individual FAMEs measurement allowed to understand the composition of the fatty acids in the acylglycerols fraction of the examined sausages (Table 3).

It is worth noting that the content of unsaturated fatty acids bound to glycerol was still significantly high with values around $60 \%$; nevertheless, an increase in the content of SFAs was observed. Palmitic and stearic acids were the prevailing SFAs being a percentage of total fatty acids about 25 and $12 \%$, respectively. A content of oleic acid lower than that in FFAs was found in acylglycerols (between $50 \%$ and $57 \%$ ). However, the most interesting result was the drastic decrease of linoleic acid content with values above $2 \%$. As a consequence, the $\mathrm{S} / \mathrm{U}$ ratio of the fatty acids constitutive of acylglycerols in the sausages increases reaching values between 0.58 and 0.77 .

These results show a different profile of fatty acids contained in acylglycerols respect to the FFAs. The KruskalWallis test (for "salsiccia" and "spianata") and MannWhitney U test (for "soppressata") were applied to both FAME and FFA concentration data grouped in three categories for each type of sausage corresponding to the three ageing periods in order to find possible statistical differences between groups and, therefore, to study the influence of ageing period on FAME and FFA contents. As shown in Table 4, many more differences were found in the FFA amounts than in the FAME ones. In particular, the concentration values of all the FFAs analyzed in the three types of sausages, except for stearic acid in salsiccia, were significantly affected by ageing process.

The decrease in the content of $\omega-6$ fatty acids mostly represented by linoleic acid is consistent with the fact that there is a significant lipase activity. Linoleic acid represents together with oleic acid one of the preferred substrates for the hydrolytic activity of the lipases $[30,31]$. Therefore, lipases act selectively releasing MUFAs and PUFAs with 18 carbon atoms. This enzymatic selectivity can explain the FFAs profile found in the examined sausages.

The dry fermented sausages cases of study are known as MUFAs and PUFAs rich foods. PUFAs are responsible for the oxidative phenomena. Oxidative stress and thermally induced conditions provoke lipid peroxidation of PUFAs in appreciable extents, with particular regard for linoleic acid, since its molecular structure displays a series of double carbon-carbon bonds which can undergo oxidative disruption.

In order to assess the extent of oxidation processes the Kreis assay (Table 5) was performed on the three different type of sausages.

This classical assay has a qualitative validity in establishing the presence of aldehydes in the lipid portions extracted from meat products. In particular, the oxidative processes that occur in sausages are responsible for the formation of alkanals and alkenals by oxidation of the double bonds of linoleic acids present in the sausages [32, 33].

One sample for each kind of sausages gave positive test (samples sal80, sop80, spi80) indicating the presence of aldehydes in the sausages. However, the purity of reagents used for the test are sometimes responsible for false determination of the presence of aldehydes, especially when the concentration of these compounds in the sample is very moderate.

We decided, at this point, to subject one of the lipid extract positive to the Kreis test to further investigation using other more sensitive instrumental techniques [34]. As an example of analysis, we subjected to the nuclear magnetic resonance investigation the sample sal80. It has been shown that high resolution ${ }^{1} \mathrm{H}$ NMR is an appropriate tool for the evaluation in fats and edible oils of primary oxidation compounds, as well as of secondary oxidation products [34, 35]. The lipid extracts were analyzed directly after their obtainment, with no work-up, to make the procedure as short in time as possible and to zeroing any further undesired lipid

Table 3. FFAs profile in acylglycerols of the analyzed sausages form Southern Italy, determined as FAMEs by GC/MS.

\begin{tabular}{|c|c|c|c|c|c|c|c|c|}
\hline & \multicolumn{3}{|c|}{ "Salsiccia" } & \multicolumn{2}{|c|}{ "Soppressata" } & \multicolumn{3}{|c|}{ "Spianata" } \\
\hline Myristic acid $\left(\mathrm{C}_{14: 0}\right)$ & $1.72 \pm 0.06$ & $1.74 \pm 0.06$ & $1.74 \pm 0.05$ & $1.53 \pm 0.05$ & $1.54 \pm 0.04$ & $1.63 \pm 0.04$ & $1.49 \pm 0.03$ & $1.48 \pm 0.04$ \\
\hline Palmitic acid $\left(\mathrm{C}_{16: 0}\right)$ & $28.49 \pm 0.31$ & $26.94 \pm 0.13$ & $25.04 \pm 0.08$ & $23.71 \pm 0.15$ & $25.55 \pm 0.28$ & $25.71 \pm 0.24$ & $23.85 \pm 0.25$ & $23.42 \pm 0.43$ \\
\hline $\begin{array}{l}\text { Palmitoleic acid } \\
\qquad\left(\mathrm{C}_{16: 1}\right)\end{array}$ & $4.10 \pm 0.06$ & $4.37 \pm 0.07$ & $3.77 \pm 0.03$ & $4.70 \pm 0.12$ & $3.25 \pm 0.07$ & $3.58 \pm 0.11$ & $3.39 \pm 0.10$ & $3.66 \pm 0.08$ \\
\hline Oleic acid $\left(\mathrm{C}_{18: 1}\right)$ & $50.33 \pm 0.64$ & $51.71 \pm 0.35$ & $54.64 \pm 0.44$ & $55.19 \pm 0.21$ & $54.07 \pm 0.36$ & $55.93 \pm 0.04$ & $57.07 \pm 0.55$ & $56.75 \pm 0.24$ \\
\hline Linoleic acid $\left(\mathrm{C}_{18: 2}\right)$ & $2.19 \pm 0.07$ & $2.41 \pm 0.06$ & $2.53 \pm 0.04$ & $2.49 \pm 0.04$ & $2.42 \pm 0.03$ & $2.35 \pm 0.03$ & $2.58 \pm 0.10$ & $2.71 \pm 0.10$ \\
\hline
\end{tabular}

Data are expressed as mean value \pm SD in percentage, $(n=3)$. Measures were performed in triplicate. S/U: saturated/unsaturated free fatty acid ratio. 
Table 4. Significant differences between the three different ageing periods (20 days (1), 40 days (2), 80 days (3)) obtained by applying the Kruskal-Wallis test (for Salsiccia and Spianata) and Mann-Whitney U test (for Soppressata) to both FAME and FFA data.

\begin{tabular}{|c|c|c|}
\hline \multicolumn{3}{|c|}{ FAME } \\
\hline Variable & Sausage & Periods $^{\mathrm{a}}$ \\
\hline Linoleic acid & Salsiccia & $1-3$ \\
\hline Palmitoleic acid & Soppressata & $1-2$ \\
\hline Stearic acid & Soppressata & $1-2$ \\
\hline \multicolumn{3}{|c|}{ FFA } \\
\hline Variable & Sausage & Periods ${ }^{\mathrm{a}}$ \\
\hline Total amount & $\begin{array}{c}\text { Salsiccia } \\
\text { Soppressata }\end{array}$ & $\begin{array}{l}1-3 \\
1-2\end{array}$ \\
\hline Miristic acid & $\begin{array}{l}\text { Salsiccia } \\
\text { Soppressata } \\
\text { Spianata }\end{array}$ & $\begin{array}{l}1-2 \\
1-2 \\
1-2\end{array}$ \\
\hline Palmitoleic acid & $\begin{array}{l}\text { Salsiccia } \\
\text { Soppressata } \\
\text { Spianata }\end{array}$ & $\begin{array}{l}1-2 \\
1-2 \\
2-3\end{array}$ \\
\hline Palmitic acid & $\begin{array}{l}\text { Salsiccia } \\
\text { Soppressata } \\
\text { Spianata }\end{array}$ & $\begin{array}{l}1-2 \\
1-2 \\
2-3\end{array}$ \\
\hline Oleic acid & $\begin{array}{l}\text { Salsiccia } \\
\text { Soppressata } \\
\text { Spianata }\end{array}$ & $\begin{array}{l}1-3 \\
1-2 \\
1-3\end{array}$ \\
\hline Linoleic acid & $\begin{array}{l}\text { Salsiccia } \\
\text { Soppressata } \\
\text { Spianata }\end{array}$ & $\begin{array}{l}1-2 \\
1-2 \\
1-3\end{array}$ \\
\hline Stearic acid & $\begin{array}{c}\text { Soppressata } \\
\text { Spianata }\end{array}$ & $\begin{array}{l}1-2 \\
1-2\end{array}$ \\
\hline
\end{tabular}

${ }^{\text {a }}$ Periods between which the significant difference was observed

oxidation. The proton NMR spectrum of the total lipid extract obtained from the sausage case of study displayed the expected set of signals attributable to the content of acyl chains, which were present in the sausage fat either as components of acylglycerols and as FFAs (Fig. 2A).

All these signals were unambiguously assigned to the corresponding spin systems of the different types of protons belonging to the various acyl chains, according to the literature values $[36,37]$. No other signals were visible in the recorded spectrum, at least upon normally scaled graphic conditions. Afterward, we undertook the analysis of the subspectrum: the downfield region between 9.00 and $10.00 \mathrm{ppm}$ showed some interesting peculiarities, principally due to the presence of a series of well-distinct signals (Fig. 2B). All these resonances were attributed to the formyl protons of aldehydes generated from the lipid secondary oxidation pathway. In the absence of specimens of these aldehydes, the data already published [38] supported us in establishing by analogy the nature of compounds generating the above set of signals. Therefore, the signal appearing at $9.75 \mathrm{ppm}$ was attributed to the series of overlapped triplets generated by the aldehydic proton in n-alkanals. The two lines at 9.56 and $9.59 \mathrm{ppm}$ were indicative of the presence of 4-hydroxy-trans2-alkenals in the products of oxidation of the mature sausage

Table 5. Kreis test of sausages

\begin{tabular}{|c|c|}
\hline Sample & Kreis test $^{\text {a }}$ \\
\hline \hline Sal20 & Negative \\
\hline Sal40 & Negative \\
\hline Sal80 & Positive ++ \\
\hline Sop40 & Negative \\
\hline Sop80 & Positive ++ \\
\hline Spi20 & Negative \\
\hline Spi40 & Negative \\
\hline Spi80 & Positive + \\
\hline + &
\end{tabular}


A
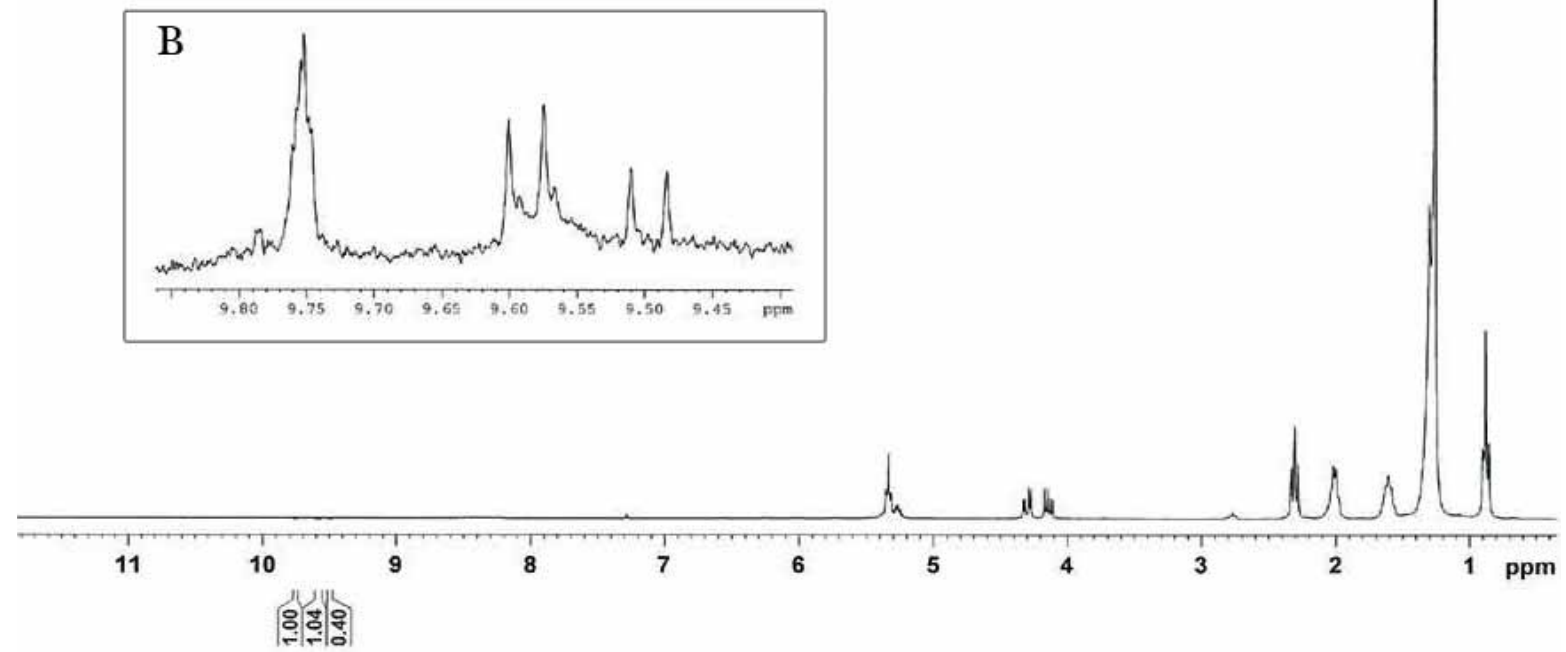

Fig. (2). High resolution ${ }^{1} \mathrm{H}$ NMR spectrum of a sample of total lipid extract obtained from sample sal80 (A), and region of the aldehydic protons $(\mathbf{B})$.

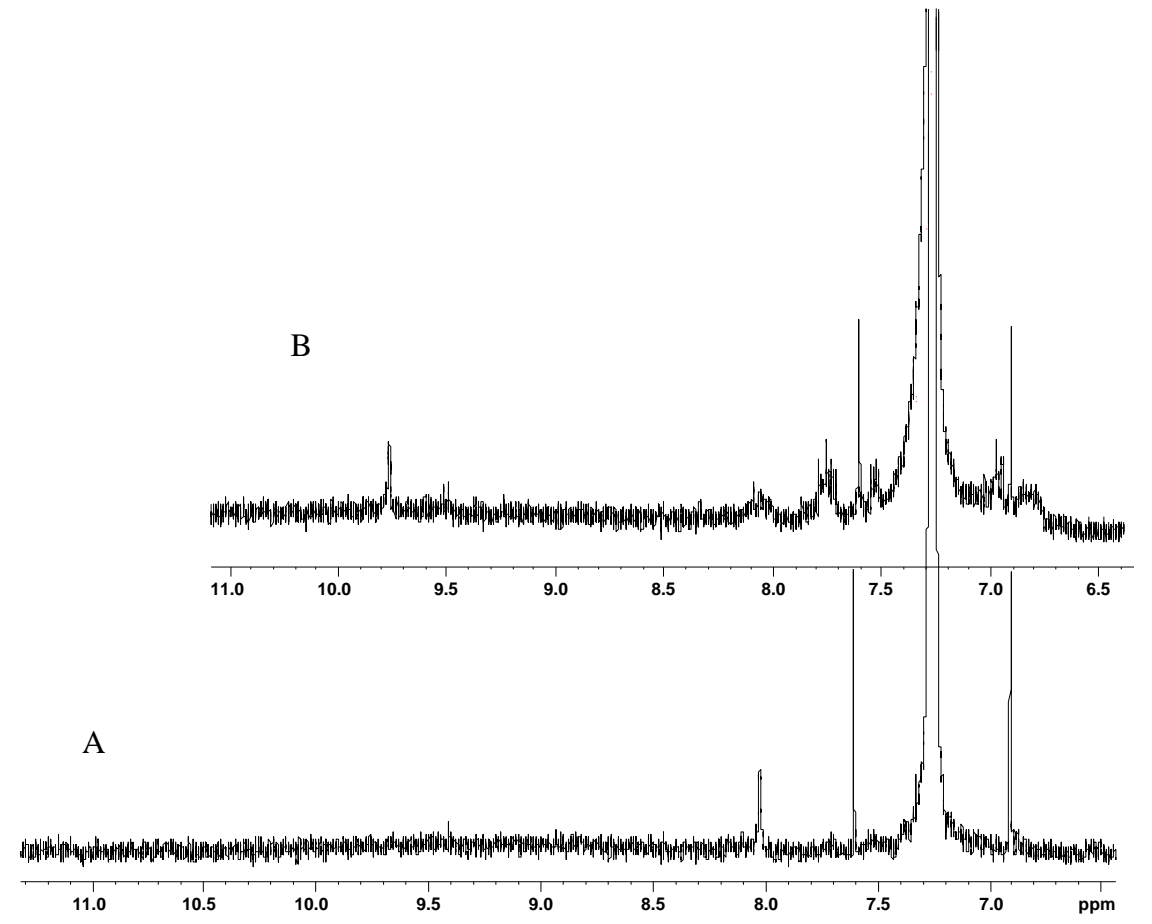

Fig. (3). Aldehydic proton windows of the high resolution ${ }^{1} \mathrm{H}$ NMR spectra recorded on samples spi40 (spectrum A) and spi80 (spectrum B).

fat. For this family of compounds the values of 9.560 and $9.586 \mathrm{ppm}$ are reported, demonstrating the perfect matching between our analysis and the literature data. The spectrum displayed two further doublets: the first, with lines at 9.57 and $9.60 \mathrm{ppm}$, was attributable to the aldehydic protons of 4hydroperoxy-trans-2-alkenals; the second, generated by the aldehydic group of trans-2-alkenals, showed its lines at 9.48 and $9.51 \mathrm{ppm}$. The appearance of the discussed signals in the spectrum, together with the absence of the triplet typically recognized for the methyl group of linolenic acid at 0.97 ppm indicated that PUFAs underwent oxidation generating the observed series of aldehydes. 
${ }^{1} \mathrm{H}$ NMR analysis was also performed on samples spi40 and spi80. The respective aldehydic proton windows are displayed in Fig. (3). As it can be observed from spectrum A the analysis of spi40, sample negative to Kreis test, did not show signals attributable to secondary lipid oxidation products. Aldehydic proton resonances of weak intensity were instead observed in the case of the slightly oxidized sample spi80 (spectrum B).

\section{CONCLUSION}

In conclusion, GC/MS analysis was used for determining the FFA content and the fatty acid profiles in acylglycerols of three kinds of dry fermented sausages from Calabria during their ripening. The data obtained indicates that lipolysis plays an essential role in developing FFAs during ripening. A preferential hydrolysis of linoleic and oleic acid was observed. The generation of aldehydic products by the oxidative degradation of unsaturated fatty acid chains was also studied by ${ }^{1} \mathrm{H}$ NMR. The spectroscopic investigation confirmed the data obtained by Kreis test.

\section{CONFLICT OF INTEREST}

The authors confirm that this article content has no conflict of interest.

\section{ACKNOWLEDGMENTS}

This study was conducted under the project: "Intesa Istituzionale di Accordo di Programma Quadro, Ricerca Scientifica e Innovazione Tecnologica nella Regione Calabria, I Atto Integrativo", Azione 3- Sostegno alla domanda di innovazione nel settore agroalimentare, "Ottimizzazione del ciclo produttivo dei salumi calabresi" POR Calabria FESR 2007-2013.

\section{REFERENCES}

[1] Aymerich T, Martin B, Garriga M, Hugas M. Microbial quality and direct PCR identification of lactic acid bacteria and non-pathogenic staphylococci from artisanal low-acid sausages. Appl Environ Microbiol 2003; 69: 4583-94.

[2] Bonomo MG, Ricciardi A, Zotta T, Sico MA, Salzano G. Technological and safety characterization of coagulase-negative staphylococci from traditionally fermented sausages of Basilicata region (Southern Italy). Meat Sci 2009; 83: 15-23.

[3] Siciliano C, Belsito E, De Marco R, Di Gioia ML, Leggio A, Liguori A. Quantitative determination of fatty acid chain composition in pork meat products by high resolution ${ }^{1} \mathrm{H}$ NMR spectroscopy. Food Chem 2013; 136: 546-54.

[4] Hierro E, De la Hoz L, Ordõnez JA. Contribution of microbial and meat endogenous enzymes to the lipolysis of dry fermented sausages. J Agric Food Chem 1997; 45: 2989-95.

[5] Garcia de Fernando G, Fox PF. Study of proteolysis during the processing of a dry fermented pork sausage. Meat Sci 1991; 30: $367-83$.

[6] Leggio A, Belsito EL, De Marco R, Liguori A, Siciliano C, Spinella M. Simultaneous extraction and derivatization of amino acids and free fatty acids in meat products. J Chromatogr A 2012; 1241: 96-102.

[7] Leggio A, Belsito EL, De Marco R, et al. Dry Fermented Sausages of Southern Italy: A Comparison of Free Amino Acids and Biogenic Amines between Industrial and Homemade Products. J Food Sci 2012; 77: 170-5.

[8] Samelis J, Aggelis G, Metaxopoulos J. Lipolytic and microbial changes during the natural fermentation and ripening of Greek dry sausages. Meat Sci, 1993; 35: 371-85.
[9] Soriano A, Cruz B, Gómez L, Mariscal C, Garcia Ruiz A. Proteolysis, physicochemical characteristics and free fatty acid composition of dry sausages made with deer (Cervus elaphus) or wild boar (Sus scrofa) meat: a preliminary study. Food Chem 2006; 96: $173-84$

[10] Trani A, Gambacorta G, Loizzo P, et al. Biochemical Traits of Ciauscolo, a Spreadable Typical Italian Dry-Cured Sausage. J Food Sci 2010; 75: 514-24.

[11] Burr M, Gilbert J, Rogers S, et al. Effects of changes in fat , fish and fiber intake on death and myocardial reinfarction. Diet and reinfarctional trial (DART). Lancet 1989; 2: 757-61.

[12] Ravnskov U. The questionable role of saturated and polyunsaturated fatty acids in cardiovascular disease. J Clin Epidemiol 1998; 51: 443-60.

[13] Griffin BA. How relevant is the ratio of dietary n-6 to n-3 polyunsaturated fatty acids to cardiovascular disease risk? Evidence from the OPTILIP study. Curr Opin Lipidol 2008; 19: 57-62.

[14] Harper CR, Jacobsen TA. Usefulness of omega-3 fatty acids and the prevention of coronary heart disease. Am J Cardiol 2005; 96 1521-9.

[15] Siri-Tarino PW, Sun Q, Hu FB, Krauss RM. Meta-analysis of prospective cohort studies evaluating the association of saturated fat with cardiovascular disease. Am J Clin Nutr 2010; 91: 535-46.

[16] Official Methods of Analysis, 16 ${ }^{\text {th }}$ Edn, Method 991.20. Association of Official Analytical Chemists Gaithersburg, MD: AOAC 1995.

[17] Official Method of Analysis, $17^{\text {th }}$ ed, Method 934.01. Association of Official Analytical Chemists, Inc., Maryland, USA: AOAC 2000.

[18] Manirakiza P, Covaci A, Schepens P. Comparative Study on Total Lipid Determination using Soxhlet, Roese-Gottlieb, Bligh \& Dyer, and Modified Bligh \& Dyer Extraction Methods. J Food Comp Anal 2001; 14: 93-100.

[19] Belsito EL, Di Gioia ML, Greco A, Leggio A, et al. N-Methyl-NNosyl-beta3-amino Acids. J Org Chem 2007; 72: 4798-802.

[20] Di Gioia ML, Leggio A, Le Pera A, et al. "One-Pot" methylation of N-Nosyl- $\alpha$-amino acid methyl esters with diazomethane and their coupling to prepare N-methyl dipeptides. J Org Chem 2003; 68: 7416-21.

[21] Di Gioia ML, Leggio A, Liguori A, Perri F, Siciliano C, Viscomi MC. Preparation of N-Fmoc-N-methyl-alpha-amino acids and Nnosyl-N-methyl-alpha-amino acids. Amino Acids 2010; 38: 13343.

[22] Di Gioia ML, Leggio A, Le Pera A, et al. Determination by gas chromatography/mass spectrometry of p-phenylenediamine in hair dyes after conversion to an imine derivative. J Chromatogr A 2005; 25: $143-8$.

[23] Pignitter M, Somoza V. Critical Evaluation of Methods for the Measurement of Oxidative Rancidity in Vegetable Oils. J Food Drug Anal 2012; 20: 772-77.

[24] Toldrá F. Proteolysis and lipolysis in flavor development of drycured meat products. Meat Sci 1998; 49: 101-10.

[25] Ordóñez JA, Hierro EV, Bruna JM, de la Hoz L. Changes in the components of dry-fermented sausages during ripening. Crit Rev Food Sci Nutr 1999; 39: 329-67.

[26] Li Y, Bruce Watkins A. Analysis of Fatty Acids in Food Lipids, in Handbook of Food Analytical Chemistry. Wrolstad RE, Acree TE Decker EA, Penner MH, Eds. New Jersey, USA: Wiley Interscience 2005; pp. 437-51.

[27] William WC. Preparation of ester derivatives of fatty acids for Chromatographic analysis, in Advances in lipid methodology-Two. Christie WW, Ed. Dundee UK: Oily Press 1993; pp. 69-111.

[28] Schlenlg H, Gellerman JL. Esterification of fatty acids with diazomethane on a small scale. Anal Chem 1960; 32: 1412-4.

[29] Franco I, Martínez A, Prieto B, Carballo J. Total and free fatty acids content during the ripening of artisan and industrially manufactured "Chorizo de cebolla". Grasas y Aceites 2002; 53: 403-13.

[30] Coutron-Gambotti C, Gandemer G. Lipolysis and oxidation in subcutaneous adipose tissue during dry-cured ham processing. Food Chem 1999; 64: 95-101.

[31] Dainty R, Blom H. Flavour chemistry of fermented sausages, In: Fermented meats. Campbell-Platt G. and Cook PE, Eds.; Chapman \& Hall: Glasgow: UK 1995; pp. 176-93. 
[32] Behman JK, Howard MJ, Greene HL. Identification of hydroxyalkenals formed from omega-3 fatty acids. Biochem Biophys Res Commun 1990; 169: 75-80.

[33] Guillén MD, Goicoechea E. Toxic oxygenated $\alpha, \beta$-unsaturated aldehydes and their study in foods: a review. Crit Rev Food Sci Nutr 2008; 48: 119-36.

[34] Guillén MD, Ruiz A. Study of the oxidative stability of salted and unsalted salmon fillets by ${ }^{1} \mathrm{H}$ nuclear magnetic resonance. Food Chem 2004; 86: 297-304.

[35] Guillén MD, Goicoechea E. Oxidation of corn oil at room temperature: Primary and secondary oxidation products and determination of their concentration in the oil liquid matrix from ${ }^{1} \mathrm{H}$ nuclear magnetic resonance data. Food Chem 2009; 116: 183-92.

[36] Knothe GJ, Kenar A. Determination of the fatty acid profile by $1 \mathrm{H}$ NMR spectroscopy. Eur J Lip Sci Technol 2004; 106: 88-9.

[37] Tyl CE, Brecker L, Wagner KH. ${ }^{1} \mathrm{H}$ NMR spectroscopy as tool to follow changes in the fatty acids of fish oils. Eur J Lip Sci Technol 2008; 110: 141-8.

[38] Guillén MD, Ruiz A. Monitoring the oxidation of unsaturated oils and formation of oxygenated aldehydes by proton NMR. Eur $\mathbf{J}$ Lipid Sci Technol 2005; 107: 36-47.

(C) Liguori et al.; Licensee Bentham Open.

This is an open access article licensed under the terms of the Creative Commons Attribution Non-Commercial License (http://creativecommons.org/licenses/ by-nc/3.0/) which permits unrestricted, non-commercial use, distribution and reproduction in any medium, provided the work is properly cited. 